The University Department of pediatrics and Child Health, Leeds, and the Department of Microbiology, Hospital for Sick Children, London, collaborated in a study of the time relations between maternal rubella infection in pregnancy and the presence and type of defects in 422 children with confirmed congenital rubelia registered in the National congenital Rubella Surveillance Program at their institutions.

In 106 cases with maternal rubella confirmed by a 4-fold rise in hemagglutination inhibition (HI) titer and/or detection of rubelia-specific lgM, 66 (62\%) had defects, 44 (67\%) were exposed to rubella between the $3 \mathrm{rd}$ and 12 th weeks of pregnancy and the remaining 22 ( $33 \%$ ) between the 13 th and 17 th weeks. Multiple defects involving the CNS, heart, eye, and hearing were recorded only in children exposed early and up to the 12 th week, deafness was also found in some exposed up to the 17 th week, and no defects occurred in 20 children exposed after this time. Deafness was the most common defect, reported in 62 (58\%) of 106 children; it was sensorineural in 55 ( $89 \%$ of the 62) and mixed conductive and nerve deafness in 7 (11\%). Of 9 children with CNS defects, 6 had inicrocephaly, 2 cerebral palsy, and 1 mental retardation.

Among 316 cases with confirmed congenital rubella but without laboratory confirmation of maternal infection, 265 ( 848 ) had defects. Deafness occurred in 75\%, eye disorders in $30 \%$, CNS defects in $25 \%$ and the heart was affected in $20 \%$.

School placements for 148 affected children are as follows: 62 ( $42 \%$ ) schools for the deaf, 33 (22\%) partial hearing units in normal schools, 3 educationally subnormal, 3 blind, and 40 ( $27 \%$ ) attend normal schools. Three-quarters of children with confirmed congenital rubella attend special schools. (Munro ND, Jones G et al. Temporal relations between maternal rubella and congenital defects. Lancet 1987; 2:201-204).

COMMENT: These data demonstrate that the risk of fetal damage from maternal rubella is very small with exposure later than the 16 th week of pregnancy. Before that time the risk of congenital defects is high. The incidence of defects in this study (62\%) is considerably higher than that reported previously $(20 \%)$ by Miller $\mathrm{E}$ et al. (Lancet 1982; $2: 781$ ). The increased incidence is explained by the high proportion ( $65 \%)$ of infants exposed up to the 16th week of pregnancy as contrasted to $38 \%$ in the earlier study. A small head circumference (<10th percentile) occurring in 188 of 102 affected infants was an additional abnomality in the Miller study but was not included among the reported rubella defects.

\title{
PERINATAL DISORDERS
}

\section{INTRACRANIAL HEMORRHAGE IN TERM INFANTS}

The authors identified 12 cases of symptomatic intracranial hemorrhage ( $\mathrm{ICH}$ ) among 23,000 infants born at the Beth Israel and Brigham and Women's Hospitals in Boston, MA, in 1982 and 1983 . The incidence of ICH was 5.2/10,000 live births or 5.9/10,000 term appropriate-for-gestation age infants $(>-2,500 \mathrm{~g}$ and $>-37$ wks gestation). Delivery was spontaneous vaginal in 8 , forceps in 3 , and cesarean section in 1. Pitocin was used in 5 cases; the indications were induction for postdate in 3 and prolonged second state in 2. Mean Apgar scores at 1 and 5 mins were 5 (range 2-9) 